\title{
Fisiologia foliar e qualidade enológica da uva em videiras infectadas por vírus
}

\author{
Marcos F. Basso ${ }^{1}$, Thor V.M. Fajardo ${ }^{2}$, Henrique P. Santos ${ }^{2}$, Celito C. Guerra ${ }^{2}$, Ricardo A. Ayub ${ }^{1} \&$ Osmar $^{2}$ \\ Nickel $^{2}$
}

${ }^{1}$ Departamento de Fitotecnia e Fitossanidade, Universidade Estadual de Ponta Grossa, 84030-900, Ponta Grossa, PR, Brasil; ${ }^{2}$ Embrapa Uva e Vinho, 95700-000, Bento Gonçalves, RS, Brasil

Autor para correspondência: Thor V.M. Fajardo, e-mail: thor@cnpuv.embrapa.br

\begin{abstract}
RESUMO
Os vírus são capazes de induzir desordens metabólicas e estruturais nas células vegetais, as quais podem variar com a espécie viral e a suscetibilidade da planta. Neste enfoque, videiras (Vitis vinifera) com e sem sintomas de infecção viral, das cvs. Cabernet Franc e Cabernet Sauvignon, em dois vinhedos comerciais, foram avaliadas comparativamente quanto ao potencial fotossintético (fotossíntese de saturação luminosa, radiação de saturação, ponto de compensação de luz, taxa de respiração no escuro, rendimento quântico aparente, clorofilas total, $a$ e $b$ ), quanto ao metabolismo de carbono foliar (açúcares solúveis totais e amido) e quanto a qualidade enológica da uva produzida (sólidos solúveis totais - ${ }^{\circ}$ Brix, densidade, $\mathrm{pH}$ e acidez total titulável no mosto - ATT; intensidade total da cor e índice de polifenóis totais na casca). Nas plantas sintomáticas foram detectados o Grapevine leafroll-associated virus 2 (GLRaV-2) e o Rupestris stem pitting-associated virus (RSPaV) pelo teste ELISA para seis vírus, os quais provocaram reduções significativas na clorofila e no potencial fotossintético, em ambas as cultivares. As folhas de plantas infectadas também apresentaram acúmulos significativos de carboidratos, caracterizando um bloqueio no transporte de carbono desses órgãos. Quanto à qualidade enológica da uva, no momento da colheita as plantas infectadas apresentaram uvas com nível de maturação significativamente menor, considerando todos os parâmetros tecnológicos do mosto $\left({ }^{\circ}\right.$ Brix, densidade, $\mathrm{pH}$, ATT e polifenóis). De modo geral, destaca-se que estes vírus podem comprometer diretamente a capacidade produtiva e a qualidade da produção destas cultivares.
\end{abstract}

Palavras-chave: Vitis, RSPaV, GLRaV-2, fotossíntese, açúcares, uva.

\begin{abstract}
Leaf physiology and enologic grape quality of virus-infected plants

Viruses may induce metabolic and structural disarray in plant cells to varying degrees depending on viral species and plant susceptibility. With this focus, grapevine plants (Vitis vinifera) cvs. Cabernet Franc and Cabernet Sauvignon, symptomless and showing symptoms of virus-infection, in two commercial vineyards were comparatively analyzed. The parameters were: 1. photosynthetic potential (light-saturated rate of photosynthesis, saturating light intensities, light compensation point, dark respiration rate, apparent quantum yield, chlorophyll a and b); 2. foliar carbon metabolism (total soluble sugars and starch), and 3. enologic quality of the produced grapes (total soluble solids - ${ }^{\circ}$ Brix, density, $\mathrm{pH}$ and titerable total acidity in the must; total color intensity and total polyphenols in berry skins) were recorded. In symptomatic plants Grapevine leafroll-associated virus 2 (GLRaV-2) and Rupestris stem pitting-associated virus (RSPaV) have been detected by ELISA carried out for six viruses. The virus infections induced significant reductions in chlorophyll content and in photosynthetic potential of both cultivars. Leaves of infected plants also showed significant accumulation of carbohydrates, suggesting a blockage of carbon transport out of these tissues. Concerning the enologic quality and based on technological parameters of the must $\left({ }^{\circ}\right.$ Brix, density, titerable total acidity and polyphenols), grapes of infected plants showed at harvest a significantly lower level of maturation. These viruses directly affect the productive capacity as well as the quality of the grapes produced by these cultivars.
\end{abstract}

Key words: Vitis, RSPaV, GLRaV-2, photosynthesis, sugars, grape.

\section{INTRODUÇÃO}

Os vírus são parasitas intracelulares obrigatórios e, uma vez estabelecida a compatibilidade com a planta hospedeira, se replicam exclusivamente pela utilização de constituintes químicos das células hospedeiras. Assim,

Parte da Tese de Mestrado do primeiro autor. Universidade Estadual de Ponta Grossa. Ponta Grossa PR. 2010. colonizam as células que compõem os diferentes tecidos da hospedeira e comprometem a integridade do organismo infectado em todos os níveis. Em decorrência disto, ocorrem várias alterações bioquímicas, fisiológicas e morfológicas, através da ativação e/ou bloqueio de determinadas atividades celulares nas plantas infectadas. Dependendo da interação vírus-hospedeira, uma grande diversidade de sintomas pode ser observada, geralmente, associada a alterações citológicas na estrutura e função dos cloroplastos (Arias et al., 2003; Sampol et al., 2003; Bertamini et al., 2004; Gonçalves et 
al., 2005; Domiciano et al., 2009). De modo geral, as infecções virais são capazes de induzir desordens na célula vegetal, que incluem alterações na fotossíntese, na respiração, nas atividades enzimáticas, no transporte de fotoassimilados e no balanço hormonal (Sampol et al., 2003). Acontece uma verdadeira "batalha" metabólica e, nas plantas suscetíveis, os vírus passam a controlar parte do metabolismo da célula parasitada. Esse processo infeccioso resultará em queda de produtividade e da qualidade da produção (Auger et al., 1992; Domiciano et al., 2009; Cretazzo et al., 2010).

Apesar de alguns avanços pontuais, ainda existem poucos trabalhos direcionados para a compreensão dos efeitos da infecção viral sobre a fisiologia das plantas hospedeiras (Arias et al., 2003). Os estudos que consideram a avaliação das alterações fisiológicas, bioquímicas e citológicas na hospedeira ainda são reduzidos comparativamente às pesquisas voltadas aos estudos de genômica e proteômica dos vírus de plantas, que visam determinar a estrutura, a organização, a replicação e o movimento viral. Os eventos moleculares associados à interação vírus/planta hospedeira, e que resultam em alterações metabólicas e no desenvolvimento de sintomas advindos do estabelecimento da doença, também são pouco entendidos (Espinoza et al., 2007), pois o acompanhamento da evolução dos processos infecciosos por patógenos apresenta dificuldade em função das consequências fisiológicas serem bastante variáveis.

Alguns estudos demonstraram, como resultado de infecções virais, redução da síntese de pigmentos fotossintéticos, correlacionando níveis de clorofila com taxa fotossintética (Naidu et al., 1984). Auger et al. (1992) verificaram que plantas infectadas por vírus apresentaram uma redução de $66,5 \%$ na taxa de assimilação líquida de $\mathrm{CO}_{2}$, em comparação às plantas sadias. Outros trabalhos já demonstraram que a proteína capsidial viral pode se acumular nos cloroplastos e nas membranas dos tilacóides de plantas infectadas, sugerindo, desta forma, que esta poderia induzir a inibição do transporte de elétrons no fotossistema II (FSII) (Técsi et al., 1994; Sampol et al., 2003).

O movimento viral célula-a-célula ocorre através dos plasmodesmas, mediado pela proteína de movimento (MP) viral, que interage com os plasmodesmas. Este fato, aliado à replicação e à concentração dos vírus da videira, preferencialmente nos tecidos do floema, poderia resultar em desorganização e alterações destes tecidos, com efeitos negativos sobre a translocação de fotoassimilados, levando ao acúmulo de amido nas folhas (Lalonde et al., 2003; Gonçalves et al., 2005). Este acúmulo de amido e açúcares nas folhas pode desencadear decréscimos significativos nas taxas fotossintéticas, via mecanismo de retro-inibição metabólica da fotossíntese (Berger et al., 2007). Embora trabalhos científicos já tenham demonstrado a diminuição da taxa fotossintética induzida por vírus, os alvos específicos (sítios e rotas metabólicas da planta) que são afetados pela ação viral neste processo são desconhecidos ou não completamente compreendidos até o momento.
Entender e tentar controlar os efeitos do processo infeccioso na hospedeira constitui um dos objetivos da fisiologia do parasitismo. O conhecimento da maneira pela qual um fitopatógeno mobiliza e altera a fisiologia e o crescimento da planta hospedeira pode, ao mesmo tempo, auxiliar no estabelecimento das bases de controle ou manejo das doenças e permitir a supressão ou diminuição dos danos causados às culturas. $\mathrm{O}$ objetivo deste trabalho foi avaliar as alterações fisiológicas foliares ocasionadas por vírus em duas cultivares de videira ( $V$. vinifera), correlacionando tais alterações com variáveis que expressam a qualidade enológica da uva.

\section{MATERIAL E MÉTODOS}

Os experimentos foram conduzidos em dois vinhedos comerciais das cultivares Cabernet Franc, enxertada no porta-enxerto SO4, implantada em 1990, conduzida em espaldeira e Cabernet Sauvignon, enxertada no portaenxerto P1103, implantada em 1997, conduzida em latada, em Bento Gonçalves (RS). As avaliações foram realizadas entre fevereiro e março de 2010. Dois grupos de 10 plantas cada, com e sem sintomas virais, para cada cultivar, foram identificados no início da maturação da uva. Na cultivar C. Franc observaram-se folhas com textura e aparência alteradas, coriáceas e com bolhosidades, enrolamento dos bordos foliares para baixo e coloração avermelhada, com as nervuras principais permanecendo verdes. $\mathrm{Na} \mathrm{cv}$. C. Sauvignon foram observados avermelhamento total da folha e a formação de tecido corticento na região de inserção do ramo do ano. As plantas infectadas também apresentavam vigor reduzido, reduções no número de brotos e de cachos/ planta e cachos desuniformes com maturação irregular.

\section{Testes sorológicos}

Todas as plantas marcadas, de ambas as cultivares, foram avaliadas visando identificar as espécies virais envolvidas na expressão dos sintomas observados. Em duas repetições, foram realizados o teste sorológico ELISA indiretoutilizando-seantissorospoliclonaiscontra Grapevine leafroll-associated virus 2 (GLRaV-2), Grapevine virus B (GVB) e Rupestris stem pitting-associated virus (RSPaV), produzidos no Laboratório de Virologia da Embrapa Uva e Vinho e o teste sorológico ELISA direto para a detecção dos vírus Grapevine leafroll-associated virus 1 e 3 (GLRaV-1 e -3) e Grapevine virus A (GVA), utilizando-se antissoros comerciais (Agritest). Todos os testes foram conduzidos, seguindo-se protocolos-padrão, a partir de $3 \mathrm{~g} /$ amostra (planta), contendo raspas de ramos maduros e fragmentos de pecíolo e nervuras foliares.

\section{Avaliação do potencial fotossintético e dos teores de clorofila}

Das dez plantas sintomáticas, de cada cultivar, foram selecionadas quatro plantas infectadas, nas quais foram escolhidas, em cada uma das plantas selecionadas, 
uma folha sintomática e outra assintomática, situadas na posição intermediária do ramo do ano para corresponder ao mesmo estádio de desenvolvimento. Para as dez plantas assintomáticas, de cada cultivar, também foram selecionadas quatro plantas sadias e em cada uma delas, uma folha para proceder as análises foliares.

As folhas selecionadas para as análises, de ambas as cultivares e grupos de plantas (sintomáticas e assintomáticas), encontravam-se expostas à radiação solar (não sombreadas pelo dossel de folhas). Estas foram submetidas a determinação de curvas de taxa de assimilação líquida de $\mathrm{CO}_{2}\left(A, \mu \mathrm{mol} \mathrm{CO} \mathrm{m}^{-2} \mathrm{~s}^{-1}\right)$ em resposta à densidade de fluxo de fótons fotossinteticamente ativo (DFFFA), com valores de $1500,800,600,400,200,100$ e $0 \mu \mathrm{mol}$ de fótons $\mathrm{m}^{-2} \mathrm{~s}^{-1}$, utilizando-se $\mathrm{o}$ analisador de gás por infravermelho (IRGA) portátil, marca Li-Cor, modelo LI-6400, operando em sistema aberto, equipado com fonte de luz modelo LI-6400-02B. Antes das avaliações, o equipamento foi calibrado retirando-se o $\mathrm{CO}_{2}$ e o vapor de água do ar circulante no aparelho com óxido de cálcio e drierite, respectivamente. Todas as medidas foram realizadas no mesmo dia, no período de 10 às $14 \mathrm{~h}$, o qual correspondeu ao período de máxima atividade fotossintética na planta (observações prévias utilizando o mesmo equipamento). Durante as análises, utilizou-se o $\mathrm{CO}_{2}$ do ambiente, o qual se manteve, em média, na concentração de $367 \mu \mathrm{mol}^{\mathrm{mol}}{ }^{-1}$. As temperaturas do ar e da folha mantiveram-se entre $25 \mathrm{e}$ $30^{\circ} \mathrm{C}$ e a velocidade do fluxo de ar empregado foi de 500 $\mu$ mol. $\mathrm{s}^{-1}$ com umidade relativa do ar de $45 \%$.

Na curva de resposta de $A$ em função da DFFFA foi ajustada uma função hiperbólica, conforme descrito por Mota et al. (2009), com a qual determinou-se a fotossíntese $(A)$ máxima ( $\mu$ mol $\left.\mathrm{CO}_{2} \mathrm{~m}^{-2} \mathrm{~s}^{-1}\right)$, radiação de saturação ( $\mu \mathrm{mol}$ fótons $\mathrm{m}^{-2} \mathrm{~s}^{-1}$ ), ponto de compensação de luz (correspondente ao valor de DFFFA em que $A$ é igual a zero, em $\mu$ mol fótons $\mathrm{m}^{-2} \mathrm{~s}^{-1}$ ), taxa de respiração no escuro (correspondente ao valor negativo de $A$ quando DFFFA é igual a zero, em $\left.\mu \mathrm{mol} \mathrm{CO} \mathrm{m}^{-2} \mathrm{~s}^{-1}\right)$ e rendimento quântico aparente $\left(\Phi_{\mathrm{a}} ; \mathrm{nmol} \mathrm{CO}_{2} / \mu \mathrm{mol}\right.$ fótons $)$. A $\Phi_{\mathrm{a}}$ foi estimada ajustando-se uma equação linear na faixa em que a variação de $A$ em função da DFFFA era linear, conforme descrito por Mota et al. (2009).

As mesmas folhas utilizadas para a determinação do potencial fotossintético também foram usadas para avaliar os teores totais e individuais de clorofila (clorofilas $a$ e $b$ ), sendo a medição feita com o auxílio de um clorofilômetro ótico portátil, utilizando-se a frequência de luz em que a clorofila melhor processa a fotossíntese. O medidor eletrônico de clorofila ClorofiLOG (Falker, CFL 1030) é um sensor comercial que analisa três faixas de frequência de luz na medição e, através de relações de absorção em diferentes frequências, determina um índice de clorofila (Índice de clorofila Falker, ICF), levando em consideração a presença das clorofilas $a$ e $b$. Os resultados obtidos foram submetidos à análise de variância e as médias foram comparadas através do teste Tukey a $5 \%$ e $1 \%$ de probabilidade de erro.

\section{Determinações de açúcares solúveis totais e amido em folhas}

Nas mesmas plantas selecionadas, foram coletadas separadamente, cerca de 10 folhas sintomáticas e assintomáticas das plantas infectadas e também folhas de plantas sadias, as quais foram secadas em estufa durante $48 \mathrm{~h}$ a $60^{\circ} \mathrm{C}$ e, posteriormente, trituradas em almofariz. Inicialmente as amostras foram submetidas a uma extração alcoólica de açúcares solúveis totais, conforme metodologia descrita por Amaral et al. (2007), utilizando-se $300 \mathrm{mg}$ de peso seco, $3 \mathrm{~mL}$ de etanol $80 \%$ e incubando-se em banho-maria a $80^{\circ} \mathrm{C}$ por $20 \mathrm{~min}$ com agitações a cada $10 \mathrm{~min}$. Posteriormente, as amostras foram centrifugadas a $13400 \mathrm{~g}$ por $5 \mathrm{~min}$ em temperatura ambiente, repetindose estas etapas quatro vezes, e coletando-se as frações dos sobrenadantes. Para a quantificação dos açúcares solúveis totais, conforme a metodologia descrita por Dubois et al. (1956), utilizaram-se $10 \mu \mathrm{L}$ de amostra acrescidos de 490 $\mu \mathrm{L}$ de água destilada, $500 \mu \mathrm{L}$ de fenol $5 \%$ e $2,5 \mathrm{~mL}$ de ácido sulfúricoconcentrado, seguido de leitura espectrofotométrica em $490 \mathrm{~nm}$. Para o cálculo da concentração de açúcares nas amostras avaliadas, efetuou-se análise de regressão entre a absorbância e a concentração conhecida de glicose, com uma solução padrão de glicose na concentração de 1 mg. $\mathrm{mL}^{-1}$.

Para a quantificação de amido, conforme metodologia descrita por Amaral et al. (2007), o resíduo precipitado da extração alcoólica dos açúcares solúveis totais foi mantido em estufa a $60^{\circ} \mathrm{C}$ por $12 \mathrm{~h}$ para a evaporação do etanol. Posteriormente, as amostras foram ressuspendidas em $500 \mu \mathrm{L}$ de água destilada e mantidas a $4^{\circ} \mathrm{C}$ por $12 \mathrm{~h}$ para a reidratação. Na sequência foram adicionados $100 \mu \mathrm{L}$ de enzima $\alpha$-amilase (3000 U/mL, Megazyme) por amostra, incubando-se em banho-maria a $80^{\circ} \mathrm{C}$ por $1 \mathrm{~h}$, sob agitação, a cada $20 \mathrm{~min}$. Após incubação, adicionaram-se $500 \mu \mathrm{L}$ de solução de acetato de sódio $0,03 \mathrm{M}, \mathrm{pH} 4,8$, e $30 \mu \mathrm{L}$ de amiloglucosidase (3260 U/mL, Megazyme), incubando-se em banho-maria a $50^{\circ} \mathrm{C}$ por 30 min sob agitação. Na etapa seguinte, foram adicionados $500 \mu \mathrm{L}$ de ácido perclórico $0,8 \mathrm{M}$, agitando-se vigorosamente e centrifugando-se a $13400 \mathrm{~g}$ por $5 \mathrm{~min}$ em temperatura ambiente. A partir dos sobrenadantes, foi determinada a concentração de glicose proveniente da degradação enzimática do amido, utilizando-se $4 \mu \mathrm{L}$ de amostra acrescidos de $16 \mu \mathrm{L}$ de água destilada e de $150 \mu \mathrm{L}$ de GOD POD (Glicose PAP Liquiform). Cada mistura foi depositada em microplaca de poliestireno, incubada a $30^{\circ} \mathrm{C}$ por 15 min e submetida a leitura da absorbância em $490 \mathrm{~nm}$. Conforme descrito por Arêas \& Lajolo (1980), a concentração de glicose obtida em cada amostra foi multiplicada por 0,9 para obtenção da concentração de amido.

\section{Análises enoquímicas}

De cada planta previamente marcada (10 sintomáticas e 10 assintomáticas), em cada vinhedo, foram colhidos, aproximadamente, dois $\mathrm{kg}$ de uva por planta, sendo os 
cachos acondicionados em sacos plásticos e mantidos a $4^{\circ} \mathrm{C}$ até o processamento das análises, ocorrido no mesmo dia da coleta. Cada amostra de uva foi submetida a uma prensagem manual para a extração do mosto, no qual foram determinados o teor de sólidos solúveis totais (SST, ${ }^{\circ} \mathrm{Brix}$ ), com o auxílio de um refratômetro digital de bancada (ABBE Refractometer, American Optical Corporation) calibrado a $20^{\circ} \mathrm{C}$; densidade a $20^{\circ} \mathrm{C}\left(\mathrm{g} . \mathrm{mL}^{-1}\right)$, com densímetro digital (PAAR DMA 45, Anton Paar); $\mathrm{pH}$, com medidor digital (pH METER 125, Corning); e acidez total titulável (meq.L $\mathrm{L}^{-1}$ ), com bureta de $50 \mathrm{~mL}$ digital (Brand) usando solução de $\mathrm{NaOH}$ $0,1 \mathrm{~N}$ e azul de bromotimol como indicador.

Nas cascas, foram determinados a intensidade total de cor (ITC) e o índice de polifenóis totais (IPT), seguindo metodologia descrita por Rizzon et al. (2000). As cascas (sem a polpa) de 100 bagas de uva, de cada amostra, foram separadas e imersas em solução hidro-alcoólica a $12 \%$ (12\% de etanol, 0,03 M de ácido tartárico, $\mathrm{pH} 3,2)$, mantidas, sob agitação constante, durante $24 \mathrm{~h}$, no escuro a $22 \pm 2{ }^{\circ} \mathrm{C}$. A fase líquida foi separada por centrifugação e efetuaram-se as análises com o sobrenadante obtido. As leituras de absorbância do extrato de cascas foram realizadas em espectrofotômetro de luz ultravioleta (Evolution 60, Thermo Scientific) nos comprimentos de onda de 420, 520 e $620 \mathrm{~nm}$ para análise de ITC e a $280 \mathrm{~nm}$ para análise do IPT, neste último caso com as amostras diluídas 1:100 em solução hidro-alcoólica. O índice ITC foi calculado pelo somatório da absorbância nos três comprimentos de onda. Para cada variável destas análises enoquímicas, realizaramse três repetições para cada amostra analisada. Os resultados obtidos foram submetidos à análise de variância e as médias foram comparadas através do teste t a $5 \%$ e $1 \%$ de probabilidade de erro.

\section{RESULTADOS E DISCUSSÃO}

\section{Detecção viral nas amostras experimentais}

Foram constatadas infecções com GLRaV-2 e $\mathrm{RSPaV}$ em todas as plantas sintomáticas avaliadas de ambas as cultivares. Entretanto, destaca-se que, os sintomas típicos do enrolamento da folha predominaram apenas no vinhedo de C. Franc, enquanto que os sintomas relacionados ao lenho rugoso (caneluras), do qual o RSPaV faz parte, se sobressaíram nas plantas de C. Sauvignon infectadas. Nenhum dos seis vírus testados foi encontrado nas plantas assintomáticas, nomeadas a partir deste ponto e, no contexto deste trabalho, como "plantas sadias".

Dentre as principais espécies virais que infectam a videira, em todo o mundo, incluem-se o GLRaV-2 e o RSPaV. O GLRaV-2 pertence a família Closteroviridae, gênero Closterovirus, enquanto que o $\mathrm{RSPaV}$ faz parte da família Betaflexiviridae, gênero Foveavirus. Por meio de um estudo de variabilidade genética, diferentes isolados destas duas espécies virais, encontrados em vinhedos brasileiros, foram caracterizados molecularmente por Radaelli et al. (2009).

\section{Potencial fotossintético e determinação dos teores de clorofila, açúcares solúveis totais e amido}

$\mathrm{Na}$ análise do potencial fotossintético de ambas as cultivares, destaca-se que os limites máximos de fotossíntese das plantas sadias foram maiores em folhas de C. Franc em relação a C. Sauvignon (Figura 1). De acordo com Regina \& Carbonneau (1999), a fotossíntese máxima de C. Sauvignon pode atingir limite máximo em torno de $11 \mu \mathrm{mol} \mathrm{CO} \mathrm{Cm}^{-2}$ $\mathrm{s}^{-1}$. Portanto, essa cultivar pode estar apresentando outras limitações fisiológicas, tais como estresse nutricional, que podem limitar o desempenho fotossintético. Além disso, estas diferenças entre cultivares podem também refletir contrastes do estádio em que se encontrava a infecção viral, do tipo e da severidade dos sintomas observados, da presença de estirpes virais específicas e de fatores inerentes a própria cultivar (ex. vigor) ou determinados pelas condições ambientais (Cabaleiro et al., 1999). Com isto, na comparação de plantas infectadas e sadias de C. Sauvignon, este contraste fisiológico não possibilitou a diferença de fotossíntese entre folhas assintomáticas de plantas infectadas e plantas sadias (Figura 1B), o que ficou evidente em folhas da C. Franc (Figura 1A).

Em ambas as cultivares, nas folhas sintomáticas de plantas infectadas, todos os parâmetros do potencial fotossintético foram negativamente afetados de forma significativa (Tabela 1). Em plantas da cv. C. Franc infectadas, verificou-se que a restrição da fotossíntese máxima foi mais evidente (-68\%) entre folhas sintomáticas e sadias, em comparação as folhas de C. Sauvignon (-56\%). Estes resultados estão semelhantes aos encontrados por Sampol et al. (2003), os quais verificaram reduções de 30 a $50 \%$ na taxa fotossintética de folhas de videira infectadas por vírus. No detalhamento dessas restrições fotossintéticas pela infecção viral, observa-se que a radiação de saturação destas folhas sintomáticas atingiu uma redução média de $38 \%$, sendo mais acentuada em C. Franc (-41\%). Palliotti et al. (2000) encontraram radiação de saturação em valores de DFFFA de 698 e $689 \mu \mathrm{mol}$ de fótons $\mathrm{m}^{-2} \mathrm{~s}^{-1}$ em videiras cvs. Cabernet Franc e Trebbiano Toscano, respectivamente. Segundo Larcher (2003), em plantas decíduas, a saturação de luz ocorre entre valores de DFFFA de 600 e $800 \mu \mathrm{mol}$ de fótons $\mathrm{m}^{-2} \mathrm{~s}^{-1}$. Abaixo destes valores, o incremento na fotossíntese é limitado pelas reações fotoquímicas (capacidade de conversão de energia luminosa em energia química), enquanto que acima destes valores ocorre a limitação da capacidade enzimática para carboxilação (Bernacchi et al., 2005). Portanto, com a redução desse limite de saturação pode-se supor que esses vírus estão limitando o "turnover" protéico/acúmulo de enzimas relacionadas com a etapa de carboxilação na fotossíntese destas cultivares.

As infecções virais foram ainda mais restritivas nos parâmetros relacionados com a etapa fotoquímica da fotossíntese, como ponto de compensação e rendimento quântico aparente. $\mathrm{O}$ ponto de compensação de folhas sintomáticas teve incrementos da ordem de $80 \%$ e $250 \%$, 

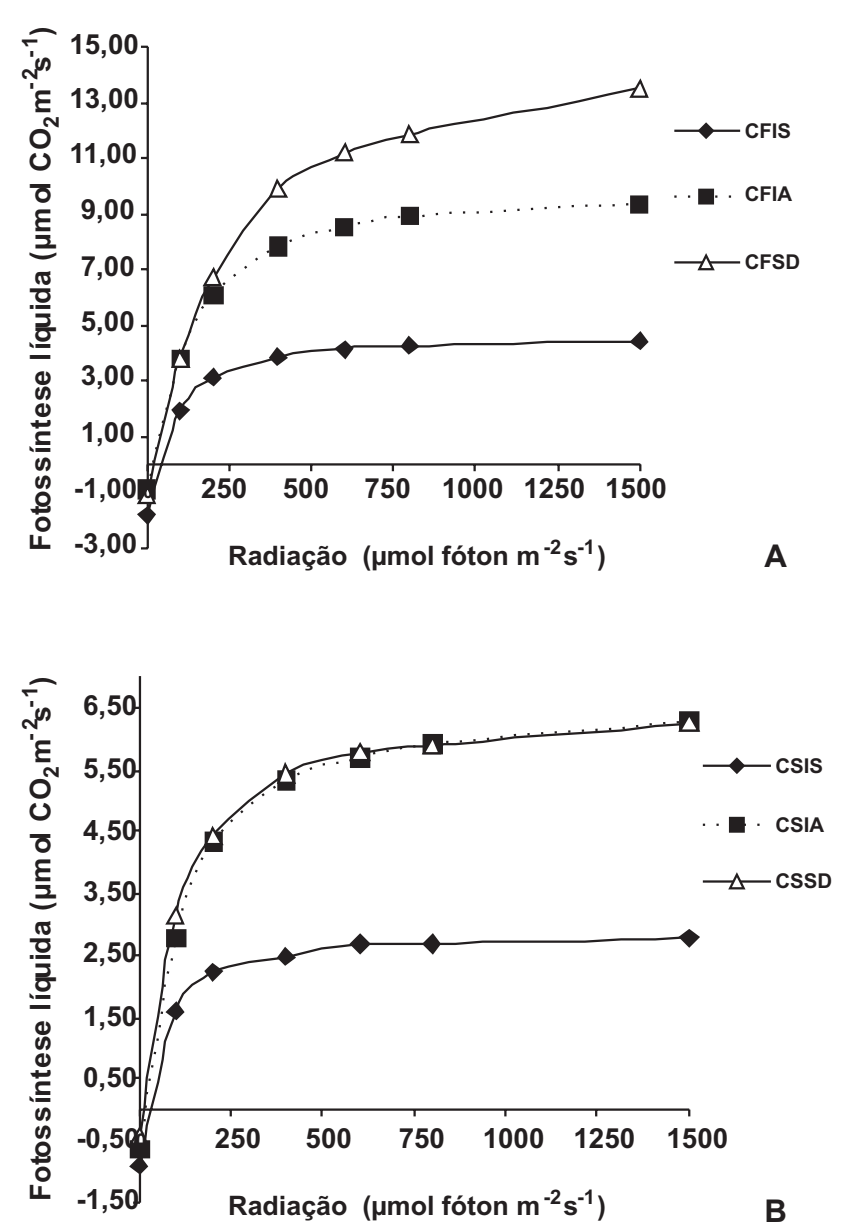

FIGURA 1 - A. Curvas com valores médios de fotossíntese líquida ou taxa de assimilação líquida de $\mathrm{CO}_{2}$ em resposta à densidade de fluxo de fótons fotossinteticamente ativo (Radiação). Videiras (Vitis vinifera) cvs. Cabernet Franc (CF) e B. Cabernet Sauvignon (CS). Planta infectada e folha sintomática (IS), planta infectada e folha assintomática (IA), planta sadia e folha sem sintomas (SD). Sintomas avaliados visualmente em plantas infectadas com Rupestris stem pitting-associated virus e Grapevine leafrollassociated virus 2

em relação as folhas de plantas sadias, respectivamente para C. Franc e C. Sauvignon (Tabela 1). Em contrapartida, o rendimento quântico aparente de ambas as cultivares foi reduzido na ordem de $24 \%$ e $35 \%$, em relação as folhas de plantas sadias, respectivamente para C. Franc e C. Sauvignon (Tabela 1). Considerando que a taxa de respiração no escuro não teve grandes variações, sendo significativa apenas em C. Franc, estas variações no ponto de compensação e no rendimento quântico aparente podem ser diretamente relacionadas com a capacidade fotoquímica dessas folhas, resultando em maior exigência de radiação para viabilizar a fixação de $\mathrm{CO}_{2}$ (Larcher, 2003). O aumento da respiração no escuro em C. Franc pode também influenciar o rendimento quântico aparente das folhas desta cultivar e tem sido relacionado à ativação de mecanismos de defesa por parte da hospedeira, frente ao ataque do patógeno. Assim como a redução na taxa fotossintética em folhas infectadas pode ser principalmente atribuída aos danos diretos que os vírus podem exercer sobre os cloroplastos (Auger et al., 1992; Sampol et al., 2003). Esses efeitos vão desde a interação da proteína capsidial (CP) do vírus com o fotossistema II (FSII) até reduções nas concentrações de clorofila e de proteína solúvel total e redução na atividade da enzima Rubisco (Bertamini et al., 2004). Reinero \& Beachy (1989) demonstraram que a CP viral acumula-se nos cloroplastos e nas membranas dos tilacóides de plantas infectadas, sugerindo, desta forma, que esta pode induzir inibição do transporte de elétrons no FSII. Gonçalves et al. (2005) também observaram que plantas de cana-de-açúcar infectadas por vírus apresentaram redução na eficiência quântica fotoquímica potencial do FSII, alterações no preenchimento do "pool" de plastoquinona e, principalmente, redução nas taxas de troca líquida de $\mathrm{CO}_{2}$, provavelmente em consequência desta redução na eficiência quântica.

Nas avaliações de teores de clorofila, verificouse, em ambas as cvs, que folhas sintomáticas de plantas infectadas apresentaram menores teores de clorofilas total, $a$ e $b$, em relação a folhas assintomáticas de plantas infectadas e folhas de plantas sadias (Tabela 2). Na comparação dos teores de clorofila obtidos para folhas de plantas sadias e folhas assintomáticas de plantas infectadas não se observou diferença significativa (Tabela 2), o que pode ser atribuído a um nível mínimo de dano induzido pela infecção viral mais recente nas folhas assintomáticas. Arias et al. (2003) também não conseguiram observar diferenças na taxa fotossintética entre plantas infectadas assintomáticas e sadias. Em plantas infectadas por vírus, Naidu et al. (1984) verificaram que as baixas taxas fotossintéticas seriam resultantes da redução nos níveis de clorofila, especificamente a clorofila $a$ e Almási et al. (2000) observaram que a infecção viral acelera a senescência das plantas e inibe ou retarda a biossíntese de clorofila, alterando assim, algumas características fisiológicas da planta hospedeira.

Para Auger et al. (1992), a diminuição nos teores de clorofila e de aminoácidos, como comumente verificado em plantas infectadas por vírus, são alguns dos fatores que contribuem para a redução do potencial fotossintético em plantas infectadas, além de exibirem aumento na atividade de enzimas responsáveis pela respiração celular. Outros fatores também são mencionados, para explicar o menor potencial fotossintético verificado em plantas infectadas por vírus, a exemplo da menor área foliar exposta das plantas infectadas, acentuando-se a diferença, em relação a plantas sadias, no final do ciclo vegetativo e do aumento da concentração de antocianinas (avermelhamento) comumente verificado em determinadas hospedeiras, em folhas sintomáticas (Brar et al., 2008). Gonçalves et al. (2005) também verificaram reduções nos conteúdos de pigmentos fotossintéticos foliares e na razão clorofia $a / b$ e aumento no conteúdo de açúcares nas folhas, como um efeito secundário da infecção viral. 
TABELA 1 - Valores de fotossíntese máxima, radiação de saturação, ponto de compensação de luz, taxa de respiração no escuro e rendimento quântico aparente de folhas de videiras (Vitis vinifera) cvs. Cabernet Franc e Cabernet Sauvignon sadias e infectadas (folhas sintomáticas e assintomáticas) com Rupestris stem pitting-associated virus e Grapevine leafroll-associated virus 2

\begin{tabular}{|c|c|c|c|c|c|c|c|c|c|c|}
\hline \multirow[t]{2}{*}{ Tratamento } & \multicolumn{2}{|c|}{$\begin{array}{l}\text { Fotossíntese } \\
\text { máxima }(\mu \mathrm{mol} \\
\left.\mathrm{CO}_{2} \mathrm{~m}^{-2} \mathrm{~s}^{-1}\right)\end{array}$} & \multicolumn{2}{|c|}{$\begin{array}{l}\text { Radiação de saturação } \\
\left(\mu \mathrm{mol} \text { fótons } \mathrm{m}^{-2} \mathrm{~s}^{-1}\right)\end{array}$} & \multicolumn{2}{|c|}{$\begin{array}{c}\text { Ponto de } \\
\text { compensação de luz } \\
\left(\mu \mathrm{mol} \text { fótons } \mathrm{m}^{-2} \mathrm{~s}^{-1}\right) \\
\end{array}$} & \multicolumn{2}{|c|}{$\begin{array}{c}\text { Taxa de respiração } \\
\text { no escuro }(\mu \mathrm{mol} \\
\left.\mathrm{CO}_{2} \mathrm{~m}^{-2} \mathrm{~s}^{-1}\right) \\
\end{array}$} & \multicolumn{2}{|c|}{$\begin{array}{c}\text { Rendimento quântico } \\
\text { aparente (nmol } \mathrm{CO}_{2} / \mu \mathrm{mol} \\
\text { fótons) }\end{array}$} \\
\hline & $\begin{array}{c}\text { C. } \\
\text { Franc }\end{array}$ & $\begin{array}{c}\text { C. } \\
\text { Sauvignon }\end{array}$ & $\begin{array}{c}\text { C. } \\
\text { Franc }\end{array}$ & $\begin{array}{c}\text { C. } \\
\text { Sauvignon }\end{array}$ & $\begin{array}{c}\text { C. } \\
\text { Franc }\end{array}$ & $\begin{array}{c}\text { C. } \\
\text { Sauvignon }\end{array}$ & $\begin{array}{c}\text { C. } \\
\text { Franc }\end{array}$ & $\begin{array}{c}\text { C. } \\
\text { Sauvignon }\end{array}$ & $\begin{array}{c}\text { C. } \\
\text { Franc }\end{array}$ & $\begin{array}{c}\text { C. } \\
\text { Sauvignon }\end{array}$ \\
\hline $\begin{array}{l}\text { Planta } \\
\text { infectada, folha } \\
\text { sintomática }\end{array}$ & $4,34 \mathrm{~B}^{*}$ & $2,66 \mathrm{~b}$ & $383,18 \mathrm{~B}$ & $234,44 b$ & $37,22 \mathrm{~A}$ & 29,19 a & $1,77 \mathrm{a}$ & $0,88 \mathrm{a}$ & $37,02 \mathrm{~b}$ & $23,15 \mathrm{~b}$ \\
\hline $\begin{array}{l}\text { Planta } \\
\text { infectada, folha } \\
\text { assintomática }\end{array}$ & $9,22 \mathrm{AB}$ & $6,01 \mathrm{a}$ & $421,28 \mathrm{~B}$ & $345,51 \mathrm{ab}$ & $17,70 \mathrm{~B}$ & $17,56 a b$ & $0,89 \mathrm{~b}$ & $0,58 \mathrm{a}$ & $47,20 \mathrm{a}$ & 34,36 a \\
\hline $\begin{array}{l}\text { Planta sadia, } \\
\text { folha sem } \\
\text { sintoma }\end{array}$ & $13,56 \mathrm{~A}$ & $6,04 \mathrm{a}$ & $646,00 \mathrm{~A}$ & $369,28 \mathrm{a}$ & $20,64 \mathrm{~B}$ & $8,32 \mathrm{~b}$ & $1,13 \mathrm{~b}$ & $0,38 \mathrm{a}$ & $49,00 \mathrm{a}$ & $35,84 \mathrm{a}$ \\
\hline CV (\%) & 21,59 & 26,62 & 11,36 & 19,57 & 15,88 & 44,95 & 22,09 & 52,63 & 11,07 & 15,54 \\
\hline
\end{tabular}

"Letras diferentes na coluna, para a mesma variável, indicam diferença significativa pelo teste Tukey (letras minúsculas, $\mathrm{P} \leq 0,05$; letras maiúsculas, $\mathrm{P} \leq 0,01)$.

TABELA 2 - Teores totais e individuais de clorofila (clorofila $a$ e $b$ ) em folhas de videiras (Vitis vinifera) cvs. Cabernet Franc e C. Sauvignon sadias e infectadas (folhas sintomáticas e assintomáticas) com Rupestris stem pitting-associated virus e Grapevine leafrollassociated virus 2

\begin{tabular}{|c|c|c|c|c|c|c|}
\hline \multirow[t]{3}{*}{ Tratamento } & \multicolumn{6}{|c|}{ Teor de clorofila } \\
\hline & \multicolumn{2}{|c|}{ Clorofila total $\left(\mathrm{ICF}^{\mathbf{1}}\right)$} & \multicolumn{2}{|c|}{ Clorofila $a$ (ICF) } & \multicolumn{2}{|c|}{ Clorofila $b$ (ICF) } \\
\hline & $\begin{array}{c}\text { Cabernet } \\
\text { Franc }\end{array}$ & $\begin{array}{c}\text { Cabernet } \\
\text { Sauvignon }\end{array}$ & $\begin{array}{c}\text { Cabernet } \\
\text { Franc }\end{array}$ & $\begin{array}{l}\text { Cabernet } \\
\text { Sauvignon }\end{array}$ & $\begin{array}{c}\text { Cabernet } \\
\text { Franc }\end{array}$ & $\begin{array}{c}\text { Cabernet } \\
\text { Sauvignon }\end{array}$ \\
\hline Planta infectada, folha sintomática & $36,5 \mathrm{~B}^{*}$ & $34,6 \mathrm{~B}$ & $28,9 \mathrm{~B}$ & $26,8 \mathrm{~B}$ & $7,6 \mathrm{~B}$ & $7,8 \mathrm{~b}$ \\
\hline Planta infectada, folha assintomática & $49,0 \mathrm{AB}$ & $45,9 \mathrm{~A}$ & $37,7 \mathrm{AB}$ & $35,1 \mathrm{~A}$ & $11,3 \mathrm{AB}$ & $10,9 \mathrm{a}$ \\
\hline Planta sadia, folha sem sintoma & $54,3 \mathrm{~A}$ & $44,7 \mathrm{~A}$ & $41,0 \mathrm{~A}$ & $34,3 \mathrm{~A}$ & $13,3 \mathrm{~A}$ & $10,4 \mathrm{a}$ \\
\hline $\mathrm{CV}(\%)$ & 10,81 & 7,19 & 10,28 & 6,57 & 13,44 & 10,72 \\
\hline
\end{tabular}

${ }^{1}$ ICF: Índice de clorofila Falker. * Letras diferentes na coluna, para a mesma variável, indicam diferença significativa pelo teste Tukey (letras minúsculas, $\mathrm{P} \leq 0,05$; letras maiúsculas, $\mathrm{P} \leq 0,01$ ).

$\mathrm{Na}$ análise de folhas assintomáticas de plantas infectadas, pode-se observar que as viroses provocam alterações no potencial fotossintético antes de se manifestarem as diferenças em pigmentos. Portanto, com base nestes resultados, é possível supor que a redução no potencial fotossintético se apresenta como uma consequência e não especificamente a causa da redução do crescimento e do potencial de produção, também observado em outros trabalhos com infecção viral.

Dentre as causas da redução do potencial fotossintético, destaca-se a possibilidade de inibição metabólica pelo acúmulo do produto final, ou retroinibição (Taiz \& Zeiger, 2004). Corroborando essa possibilidade, observou-se que as folhas sintomáticas e assintomáticas das plantas infectadas, de ambas as cultivares, apresentaram maiores teores de açúcares solúveis totais e acúmulo de amido quando comparadas com folhas de plantas sadias (Tabela 3). Estes resultados demonstraram que, apesar da restrição fotossintética foliar, o processo infeccioso viral nestas cultivares favoreceu o acúmulo de açúcares solúveis e amido tanto em tecidos onde a infecção viral encontra-se mais avançada (folhas sintomáticas), quanto em tecidos onde a infecção é mais recente (folhas assintomáticas). Destacase que o incremento de amido foliar é consequência do acúmulo de açúcares solúveis redutores, com o intuito de manter o equilíbrio no potencial redox do citoplasma celular (Buckeridge et al., 2004). Portanto, a redução na atividade fotossintética, observada neste trabalho, pode estar relacionada, de modo indireto, com o bloqueio da "drenagem" (saída) de carboidratos das folhas infectadas. Os vírus ao se concentrarem no floema podem desorganizar os tecidos condutores, interferindo em seu funcionamento normal (carregamento), resultando em 
Fisiologia foliar e qualidade enológica da uva em videiras infectadas por vírus

TABELA 3 - Teores de açúcares solúveis totais e de amido em folhas de videiras (Vitis vinifera) cvs. Cabernet Franc e C. Sauvignon sadias e infectadas (folhas sintomáticas e assintomáticas) com Rupestris stem pitting-associated virus e Grapevine leafroll-associated virus 2

\begin{tabular}{lcccc}
\hline \hline Tratamento & \multicolumn{1}{c}{$\begin{array}{c}\text { Açúcares solúveis totais } \\
\text { (mg de glicose/100mg de massa seca) }\end{array}$} & \multicolumn{2}{c}{$\begin{array}{c}\text { Amido } \\
\text { (mg/100mg de massa seca) }\end{array}$} \\
\cline { 2 - 5 } & Cabernet Franc & Cabernet Sauvignon & Cabernet Franc & Cabernet Sauvignon \\
\hline Planta infectada, folha sintomática & $5,18 \mathrm{a}^{*}$ & $6,39 \mathrm{a}$ & $1,90 \mathrm{a}$ & $0,60 \mathrm{~A}$ \\
Planta infectada, folha assintomática & $4,61 \mathrm{a}$ & $5,17 \mathrm{ab}$ & $1,60 \mathrm{a}$ & $0,30 \mathrm{AB}$ \\
Planta sadia, folha sem sintoma & $2,53 \mathrm{~b}$ & $4,10 \mathrm{~b}$ & $0,19 \mathrm{~b}$ & $0,03 \mathrm{~B}$ \\
\hline CV $(\%)$ & 23,0 & 21,22 & 47,3 & 52,16 \\
\hline
\end{tabular}

"Letras diferentes na coluna, para a mesma variável, indicam diferença significativa pelo teste Tukey (letras minúsculas, $\mathrm{P} \leq 0,05$; letras maiúsculas, $\mathrm{P} \leq 0,01)$.

acúmulo de fotoassimilados nas folhas infectadas. Este bloqueio no transporte de carboidratos pode interferir no metabolismo foliar através dos princípios da teoria do "sugar sensing" (Jang \& Sheen, 1994), os quais correlacionam níveis de açúcares solúveis no citoplasma com o controle da expressão de genes relacionados com a fotossíntese. Neste sentido, Espinoza et al. (2007) observaram, em videiras infectadas com GLRaV-3, mudanças na expressão de genes relacionados à infecção viral compatível. Foram induzidos genes principalmente associados com membrana celular e sistema de endomembranas, codificando proteínas envolvidas na função de transporte, enquanto que os genes reprimidos foram associados com os cloroplastos, codificando proteínas associadas a funções metabólicas, tais como proteínas fotossintéticas, constituintes dos fotossistemas e enzimas da biossíntese de clorofilas.

Gonçalves et al. (2005) e Berger et al. (2007) também relataram que altas concentrações de açúcares nas folhas podem causar decréscimos na taxa fotossintética, via mecanismo de retro-inibição metabólica da fotossíntese. O RSPaV e o GLRaV-2 são vírus que invadem, replicam-se e se concentram nos tecidos do floema. Na replicação viral, o vírus codifica a proteína de movimento (MP) viral, que ao interagir com os plasmodesmas para promover o movimento viral célulaa-célula, pode alterar, mesmo que temporariamente, a funcionalidade dos plasmodesmas, interferindo no fluxo de fotoassimilados para o floema (Lalonde et al, 2003; Gonçalves et al., 2005) e, consequentemente, para os órgãos-dreno da planta, como ramos, raízes e frutos.

Os impactos sobre o potencial fotossintético das folhas, de ambas as cultivares, potencialmente restringem o acúmulo de reservas e a capacidade de crescimento, refletindo, consequentemente, em queda de qualidade da produção e produtividade. Cabaleiro et al. (1999) mencionaram que, embora o desenvolvimento de videiras durante os primeiros anos de cultivo não tenha sido afetado pela infecção viral, a menor taxa fotossintética líquida, apresentada pelas plantas infectadas por vírus, pode comprometer a produção ao longo dos anos.

\section{Análises enoquímicas}

$\mathrm{O}$ aspecto geral das uvas colhidas, de plantas sadias e infectadas, das duas cultivares e submetidas às análises enoquímicas, evidenciou o amadurecimento irregular e incompleto das uvas provenientes das plantas infectadas. As uvas colhidas de plantas infectadas, de ambas as cultivares analisadas, apresentaram resultados que diferiram estatisticamente das plantas sadias, em cinco das seis variáveis analisadas $(\mathrm{pH}$ apenas para a cv. C. Franc) sempre com resultados favoráveis às plantas sadias (Tabela 4). As uvas colhidas de plantas infectadas apresentaram reduções de sólidos solúveis totais (SST) de 2,53 (C. Franc) e $2,72{ }^{\circ}$ Brix (C. Sauvignon), quando comparadas às uvas colhidas de plantas sadias (Tabela 4). A variação observada para a densidade reflete diretamente a variação obtida em relação aos SST. Esta variação em acúmulo de açúcares na uva corrobora as reduções observadas no potencial fotossintético e as restrições no transporte de carboidratos entre órgãos (folha e fruto) em plantas infectadas, discutido anteriormente.

Considerando-se que, na fermentação alcoólica, 2 ${ }^{\circ}$ Brix produzem aproximadamente $1{ }^{\circ} \mathrm{GL}$, seria hipoteticamentenecessário compensaresta reduçãode SST com a adição de sacarose ao mosto, consequentemente, depreciando a qualidade do vinho e aumentando os custos de produção. Em termos econômicos, Kuhn \& Protas (1988) determinaram reduções, advindas de plantas infectadas por vírus de até $63 \%$ na produção e de até $70 \%$ na receita auferida, pois na comercialização da uva com maior ${ }^{\circ}$ Brix são obtidos melhores preços. Resultados semelhantes foram obtidos por Komar et al. (2007) que, ao avaliarem as características enológicas de uvas provenientes de plantas infectadas por vírus, observaram reduções nos teores de sólidos solúveis totais e na intensidade da cor. Efeitos negativos mais acentuados podem ser observados em plantas apresentando infecções virais múltiplas ou em vinhedos mais antigos (Akbas et al., 2009).

O acúmulo de açúcares nas folhas (Tabela 3) e o bloqueio do transporte desses para órgãos de reserva acarretam a insuficiente mobilização de amido em órgãos de reserva, afetando o vigor da planta na estação 
TABELA 4 - Resultados da avaliação da qualidade enológica de uvas colhidas de videiras, cvs. Cabernet Franc e Cabernet Sauvignon, sadias e infectadas com Rupestris stem pitting-associated virus e Grapevine leafroll-associated virus 2. Média de 10 plantas

\begin{tabular}{|c|c|c|c|c|}
\hline \multirow[t]{2}{*}{ Variável } & \multicolumn{2}{|c|}{ Cabernet Franc } & \multicolumn{2}{|c|}{ Cabernet Sauvignon } \\
\hline & Planta infectada & Planta sadia & Planta infectada & Planta sadia \\
\hline Sólidos solúveis totais (SST) $\left({ }^{\circ}\right.$ Brix $)$ & $15,35 \mathrm{a}^{*}$ & $17,88 \mathrm{~b}$ & $13,38 \mathrm{~A}$ & $16,10 \mathrm{~B}$ \\
\hline Densidade a $20^{\circ} \mathrm{C}\left(\mathrm{g} \cdot \mathrm{mL}^{-1}\right)$ & $1,0665 \mathrm{a}$ & $1,0759 \mathrm{~b}$ & $1,0594 \mathrm{~A}$ & $1,0697 \mathrm{~B}$ \\
\hline $\mathrm{pH}$ & $3,30 \mathrm{a}$ & $3,38 \mathrm{~b}$ & $3,21 \mathrm{a}$ & $3,26 \mathrm{a}$ \\
\hline Acidez total titulável (meq. $\left.\mathrm{L}^{-1}\right)$ & $95,09 \mathrm{a}$ & $100,28 \mathrm{a}$ & $142,81 \mathrm{a}$ & $126,58 \mathrm{a}$ \\
\hline Intensidade total da cor (ITC) $\left(\mathrm{g} . \mathrm{L}^{-1}\right)$ & $2,572 \mathrm{a}$ & $3,044 \mathrm{~b}$ & $1,383 \mathrm{~A}$ & $2,126 \mathrm{~B}$ \\
\hline Índice de polifenóis totais (IPT) $\left(\mathrm{g} \cdot \mathrm{L}^{-1}\right)$ & $0,062 \mathrm{~A}$ & $0,101 \mathrm{~B}$ & $0,040 \mathrm{~A}$ & $0,061 \mathrm{~B}$ \\
\hline
\end{tabular}

"Letras diferentes na mesma linha, para a mesma cultivar, indicam diferença significativa pelo teste $\mathrm{t}$ (letras minúsculas, $\mathrm{P} \leq 0,05$; letras maiúsculas, $\mathrm{P} \leq 0,01)$.

de crescimento seguinte. As maiores consequências da infecção viral em videira são o amadurecimento irregular dos cachos, a redução da produtividade e a diminuição da cor em uvas tintas (Reynolds et al., 1997; Cabaleiro et al., 1999; Komar et al., 2010). O amadurecimento irregular dos cachos pode ocasionar aumento da acidez total titulável do mosto da uva (Cabaleiro et al., 1999), entretanto este efeito não foi significativo nas avaliações realizadas (Tabela 4). De maneira geral o mosto da uva de plantas infectadas tende a apresentar menor $\mathrm{pH}$ quando comparado com o de plantas sadias (Credi \& Babini, 1997; Cabaleiro et al., 1999; Guidoni et al., 2000; Kovacs et al., 2001), mas esse parâmetro apresentou diferença significativa apenas na C. Franc, possivelmente pelas diferenças em infecções virais e respostas fisiológicas desta cultivar.

Uvas provenientes de plantas infectadas também apresentaram menor intensidade total de cor (ITC) e menor índice de polifenóis totais (IPT). As expressivas reduções verificadas na ITC foram de 15,5\% (C. Franc) e 34,9\% (C. Sauvignon) e no IPT foram de $38,6 \%$ (C. Franc) e 34,4\% (C. Sauvignon) (Tabela 4). Em se tratando de uvas viníferas, esses efeitos negativos têm consequências importantíssimas para a qualidade final de vinhos finos. De modo geral, as viroses podem afetar os teores de taninos (polifenóis) e de antocianinas (responsáveis pela cor), além dos compostos aromáticos, não avaliados neste trabalho (Brar et al., 2008; Lee \& Martin, 2009), os quais comprometem diretamente a qualidade potencial do vinho produzido.

Os resultados apresentados demonstraram que a infecção dupla dos vírus GLRaV-2 e RSPaV afetou negativamente, de forma direta e indireta, diversas variáveis relacionadas à fisiologia foliar e à distribuição de fotoassimilados na videira com reflexos significativos sobre a qualidade enológica da uva. Assim sendo, ressaltase a importância da utilização de material propagativo livre de vírus na implantação de vinhedos visando-se controlar os efeitos negativos advindos da infecção viral, embora alguns vírus que infectam a videira também possam ser transmitidos por vetores.

\section{REFERÊNCIAS BIBLIOGRÁFICAS}

Akbas B, Kunter B, Ilhan D (2009) Influence of leafroll on local grapevine cultivars in agroecological conditions of Central Anatolia region. Horticultural Science 36:97-104.

Almási A, Apatini D, Bóka K, Boddi B, Gaborjányi R (2000) BSMV infection inhibits chlorophyll biosynthesis in barley plants. Physiological and Molecular Plant Pathology 56:227-233.

Amaral LIV, Gaspar M, Costa PMF, Aidar MPM, Buckeridge MS (2007) Novo método enzimático rápido e sensível de extração e dosagem de amido em materiais vegetais. Hoehnea 34:425-431.

Arêas JAG, Lajolo FM (1980) Determinação enzimática específica de amido, glicose, frutose e sacarose em bananas pré-climáticas e climatéricas. Anais de Farmácia e Química de São Paulo 20:307318.

Arias MC, Lenardon S, Taleisnik E (2003) Carbon metabolism alterations in sunflower plants infected with the Sunflower chlorotic mottle virus. Journal of Phytopathology 151:267-273.

Auger JS, Aballay EE, Pinto MC, Pastenes CV (1992) Efecto del virus de la hoja en abanico (VHA) en el desarrollo y productividad de plantas de vid cv. Thompson Seedless. Fitopatología 27:85-89.

Berger S, Sinha AK, Roitsch T (2007) Plant physiology meets phytopathology: plant primary metabolism and plant-pathogen interactions. Journal of Experimental Botany 58:4019-4026.

Bernacchi CJ, Morgan PB, Ort DR, Long SP (2005) The growth of soybean under free air $\left[\mathrm{CO}_{2}\right]$ enrichment (FACE) stimulates photosynthesis while decreasing in vivo Rubisco capacity. Planta 220:434-446.

Bertamini M, Muthuchelian K, Nedunchezhian N (2004) Effect of Grapevine leafroll on the photosynthesis of field grown grapevine plants (Vitis vinifera L. cv. Lagrein). Journal of Phytopathology 152:145-152.

Buckeridge MS, Aidar MPM, Santos HP, Tiné MAS (2004) Acúmulo de reservas. In: Ferreira AG, Borghetti F. (Org.). Germinação - do Básico ao Aplicado. 1ed. Porto Alegre RS. Artmed Editora. pp. 31-50.

Brar HS, Singh Z, Swinny E, Cameron I (2008) Girdling and Grapevine leafroll-associated viruses affect berry weight, colour development and accumulation of anthocyanins in 'Crimson 
Seedless' grapes during maturation and ripening. Plant Science 175:885-897.

Cabaleiro C, Segura A, García-Berrios JJ (1999) Effects of Grapevine leafroll-associated virus 3 on the physiology and must of Vitis vinifera L. cv. Albariño following contamination in the field. American Journal of Enology and Viticulture 50:4044.

Credi R, Babini AR (1997) Effects of virus and virus-like infections on growth, yield, and fruit quality of Albana and Trebbiano Romagnolo grapevines. American Journal of Enology and Viticulture 48:7-12.

Cretazzo E, Padilha C, Carambula C, Hita I, Salmerón E, Cifre J (2010) Comparison of the effects of different virus infections on performance of three Majorcan grapevine cultivars in field conditions. Annals of Applied Biology 156:1-12.

Domiciano GP, Resende RS, Rodrigues FA, Da Matta FM (2009) Alterações na fotossíntese de plantas infectadas por patógenos. Revisão Anual de Patologia de Plantas 17:305-339.

Dubois M, Giles KA, Hamilton JK (1956) Colorimetric method for determination of sugars and related substances. Analytical Chemestry 28:350-356.

Espinoza C, Vega A, Medina C, Schlauch K, Cramer G, ArceJohnson P (2007) Gene expression associated with compatible viral diseases in grapevine cultivars. Functional \& Integrative Genomics 7:95-110.

Gonçalves MC, Vega J, Oliveira JG, Gomes MMA (2005) Sugarcane yellow leaf virus infection leads to alterations in photosynthetic efficiency and carbohydrate accumulation in sugarcane leaves. Fitopatologia Brasileira 30:10-16.

Guidoni S, Mannini F, Ferrandino A, Argamante N, Di Stefano $\mathrm{R}$ (2000) Effects of virus status on leaf and berry phenolic compounds in two wine grapevine Vitis vinifera cultivars. Acta Horticulture 526:445-452.

Jang JC, Sheen J (1994) Sugar sensing in higher plants. The Plant Cell 6:1665-1679.

Komar V, Vigne E, Demangeat G, Fuchs M (2007) Beneficial effect of selective virus elimination on the performance of Vitis vinifera cv. Chardonnay. American Journal of Enology and Viticulture 58:202-210.

Komar V, Vigne E, Demangeat G, Lemaire O, Fuchs M (2010) Comparative performance of virus-infected Vitis vinifera cv. Savagnin Rose grafted onto three rootstocks. American Journal of Enology and Viticulture 61:68-73.

Kovacs LG, Hanami H, Fortenberry M, Kaps ML (2001) Latent infection by leafroll agent GLRaV-3 is linked to lower fruit quality in French-American hybrid grapevines Vidal blanc and St. Vincent. American Journal of Enology and Viticulture 52:254-259.

Kuhn GB, Protas JFS (1988) Perdas causadas pela virose do enrolamento da folha na cultivar Cabernet Franc. Bento Gonçalves. Comunicado Técnico Embrapa 7.
Lalonde S, Tegeder M, Throne-Holst M, Frommer WB, Patrick JW (2003) Phloem loading and unloading of sugars and amino acids. Plant Cell \& Environment 26:37-56.

Larcher W (2003) Physiological plant ecology. Berlin. SpringerVerlag.

Lee J, Martin RR (2009) Influence of Grapevine leafrollassociated viruses (GLRaV-2 and -3) on the fruit composition of Oregon Vitis vinifera L. cv. Pinot noir: Phenolics. Food Chemistry 112:889-896.

Mota CS, Amarante CVT, Santos HP, Albuquerque JA (2009) Disponibilidade hídrica, radiação solar e fotossíntese em videiras 'Cabernet Sauvignon' sob cultivo protegido. Revista Brasileira de Fruticultura 31:432-439.

Naidu RA, Krishnan M, Nayudu MY, Gnanama A (1984) Studies on peanut green mosaic virus infected peanut (Arachis hypogaea L.) leaves. II. Chlorophyll-protein complexes and polypeptide composition of thylakoid membranes. Physiology Plant Pathology 25:191-198.

Palliotti A, Cartechini A, Ferranti F (2000) Morpho-anatomical and physiological characteristics of primary and lateral shoot leaves of 'Cabernet Franc' and 'Trebbiano Toscano' grapevines under two irradiance regimes. American Journal of Enology and Viticulture 51:122-130.

Radaelli P, Fajardo TVM, Nickel O, Eiras M, Pio-Ribeiro G (2009) Variabilidade do gene da proteína capsidial de três espécies virais que infectam videiras no Brasil. Tropical Plant Pathology 34:297-305.

Reinero A, Beachy RN (1989) Reduced photosystem II activity and accumulation of viral coat protein in chloroplasts of leaves infected with Tobacco mosaic virus. Plant Physiology 89:111116.

Regina MA, Carbonneau A (1999) Trocas gasosas em Vitis vinifera sob regime de estresse hídrico. II. Fotorrespiração e Comportamento Varietal. Pesquisa Agropecuária Brasileira 34:3744.

Reynolds AG, Lanterman WS, Wardle DA (1997) Yield and berry composition of five Vitis cultivars as affected by Rupestris stem pitting virus. American Journal of Enology and Viticulture 48:449-458.

Rizzon LA, Miele A, Meneguzzo J (2000) Avaliação da uva cv. Isabel para a elaboração de vinho tinto. Ciência Tecnologia de Alimentos 20:115-121.

Sampol T, Bota J, Medrano H, Flexas J (2003) Analysis of the virus-induced inhibition of photosynthesis in malmsey grapevines. New Phytologist 160:403-412.

Taiz L, Zeiger E (2004) Fisiologia vegetal. Porto Alegre RS. Artmed Editora.

Técsi CI, Maule AJ, Smith AM, Leegood RC (1994) Metabolic alterations in cotyledons of Cucurbita pepo infected by Cucumber mosaic virus. Journal of Experimental Botany 45:1541- 1551. 